\title{
Facile Synthesis of Fluorene-based $\pi$-Conjugated Polymers via Sequential Bromination/Direct Arylation Polycondensation
}

\author{
Hitoshi Saito, Junpei Kuwabara, and Takaki Kanbara
}

Tsukuba Research Center for Interdisciplinary Materials Science (TIMS), Graduate School of Pure and Applied Sciences, University of Tsukuba, 1-1-1 Tennodai, Tsukuba, Ibaraki 305-8573, Japan

Correspondence to: T.Kanbara (E-mail: kanbara@ims.tsukuba.ac.jp)

KEYWORDS: Conjugated polymers; Polycondensation; Metal-organic catalysts/organometallic catalysts; Direct arylation; One pot synthesis

Catalytic direct arylation of aromatic compounds via cleavage of $\mathrm{C}-\mathrm{H}$ bonds has attracted increasing attention as a simple synthetic method that helps eliminate prior preparations of organometallic reagents. ${ }^{1-6}$ Recently, several groups have attempted to utilize this reaction in polycondensation for the synthesis of $\pi$-conjugated polymers that are considered promising materials for optoelectronic devices such as organic photovoltaic cells, field effect transistors, and light emitting diodes (Scheme 1 (a)). ${ }^{7-16}$ However, this polycondensation reaction still requires prior preparation of dihalogenated aromatic monomers as coupling partners: Introduction of $\mathrm{C}-\mathrm{Br}$ groups into the corresponding aromatic compounds and purification of the dibrominated aromatic monomers would involve extra synthetic steps. These observations prompted our interest in the facile synthesis of $\pi$-conjugated polymers via sequential bromination and direct arylation polycondensation (Scheme 1 (b)); this protocol enables the use of each aromatic monomer without pre-introduction of reactive $\mathrm{C}-\mathrm{Br}$ bonds as well as organometallic functional groups. We thus explored an efficient bromination reaction and employed it for the bromination of arenes with quaternary ammonium tribromide; the reaction proceeded smoothly under mild conditions, giving the desired bromoarenes in good yields. ${ }^{17-22}$ 9,9-Dioctylfluorene is an appropriate targeting monomer because 2,7dibromo-9,9-dioctylfluorene possesses good (a) Direct arylation polycondensation

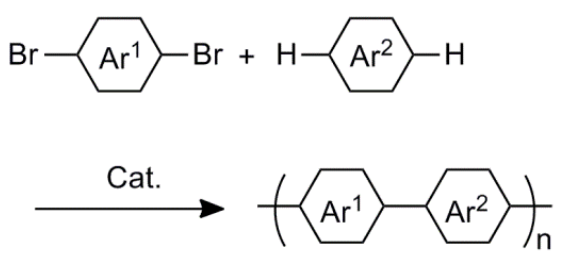

(b) This work: Sequential bromination / Direct arylation polycondensation

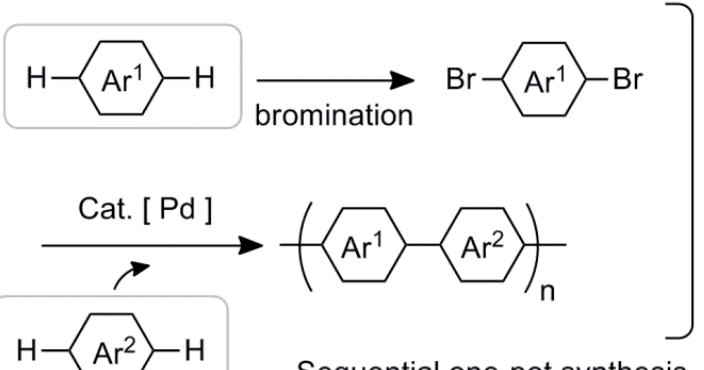

Sequential one-pot synthesis

Scheme 1. Schematic illustrations of sequential bromination and direct arylation polycondensation.

reactivity toward the direct arylation polycondensation and high selectivity against side reactions; accordingly, a variety of fluorene-based $\pi$-conjugated polymers have been synthesized. ${ }^{15,23-32}$ We herein report the synthesis of fluorene-based $\pi$-conjugated polymers via sequential bromination of 9,9dioctylfluorene and Pd-catalyzed direct arylation polycondensation. 
The following two conditions must be satisfied for sequential bromination and Pd-catalyzed direct arylation polycondensation. Each reaction should efficiently proceed, and residues and/or byproducts originating from the bromination reaction step should have negligible impact on the successive polycondensation step. For instance, bromination of aromatic compounds has been generally carried out with bromine or $\mathrm{N}$ bromosuccinimide (NBS); $;^{33-35}$ however, the residual bromine and/or the produced byproducts such as succinimide are considered to inhibit the following direct arylation. In contrast, bromination with benzyltrimethylammonium tribromide (BTMA $\left.\mathrm{Br}_{3}\right)^{16-18}$ was expected to be preferable for our protocol; the solid brominating agent allows for accurate stoichiometric reaction, and benzyltrimethylammonium bromide (BTMA $\mathrm{Br}$ ), a byproduct of the bromination, dose not inhibit the successive polycondensation step because tetraalkylammonium halides have been often used as a phase transfer catalyst in polycondensation processes. ${ }^{7,12,36-38}$ Therefore, we began our investigation with dibromination of 9,9-dioctylfluorene using a stoichiometric amount of BTMA $\mathrm{Br}_{3}$. According to the literature, ${ }^{16}$ the reaction gave 2,7-dibromo-9,9dioctylfluorene in excellent isolated yield (98\%) in the presence of $\mathrm{ZnCl}_{2}$, which served as a Lewis acid, ${ }^{17}$ and acetic acid, and only a trace amount of mono-brominated product was observed. In addition, the reaction smoothly proceeded in the absence of acetic acid and the dibrominated product was isolated in good yield (98\%, Scheme S1, Supporting Information); consequently, we adopted the reaction conditions in the absence of acetic acid.

Subsequently, to assess whether the presence of the conserved residues of the bromination reaction considerably affected the following polycondensation process or not, $\mathrm{Pd}$-catalyzed direct arylation polycondensation of 5octylthieno[3,4-c]pyrrole-4,6-dione (TPD) with the isolated pure 2,7-dibromo-9,9dioctylfluorene was conducted in the presence of some additives (Scheme 2). Table 1

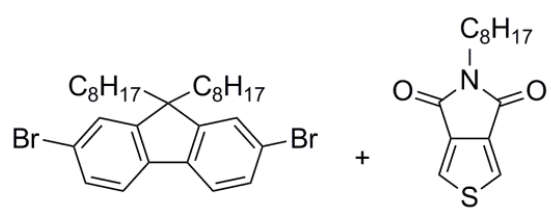

+ Addition of bromination reaction residues

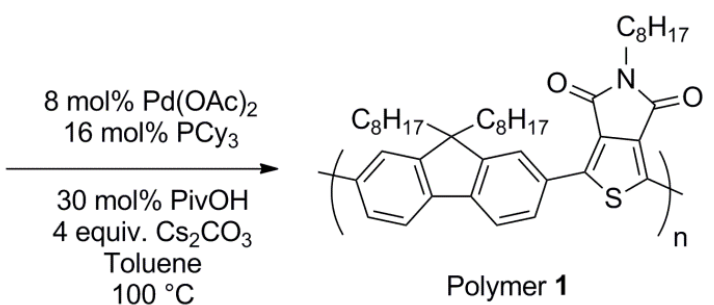

Scheme 2. Direct arylation polycondensation in the presence of byproduct of bromination reaction.

Table 1. Results of direct arylation polycondensation of 2,7-dibromo-9,9-dioctylfluorene with TPD in the presence of additive ${ }^{a)}$

\begin{tabular}{cccccc}
\hline Entry & Additive (equiv.) & $\begin{array}{c}\text { Reaction time } \\
/ \mathrm{h}\end{array}$ & $\begin{array}{c}\text { Yield }^{\mathrm{b})} \\
/ \%\end{array}$ & $M_{\mathrm{n}}{ }^{\mathrm{c}}$ & $M_{\mathrm{w}} / \mathrm{M}_{\mathrm{n}}{ }^{\mathrm{c}}$ \\
\hline 1 & - & 24 & 96 & 129200 & 2.60 \\
2 & Succinimide (2) & $24(240)$ & $0(0)$ & - & - \\
3 & $\mathrm{BTMA} \mathrm{Br} \mathrm{(2)}$ & 24 & 95 & 89500 & 2.32 \\
4 & ${\mathrm{BTMA} \mathrm{Br}(2) / \mathrm{ZnCl}_{2}(2.5)}_{48}$ & 95 & 50500 & 2.33
\end{tabular}

\footnotetext{
a) Reactions were carried out at $100^{\circ} \mathrm{C}$ in toluene $(2.5 \mathrm{~mL})$ for $0.50 \mathrm{mmol}$ scale using $\operatorname{Pd}(\mathrm{OAc})_{2}(8$ mol\%), $\mathrm{PCy}_{3}\left(16 \mathrm{~mol} \%\right.$ ), $\mathrm{PivOH}$ ( $30 \mathrm{~mol} \%$ ) and $\mathrm{Cs}_{2} \mathrm{CO}_{3}$ (4 equiv.); ${ }^{\mathrm{b})}$ The products were obtained by reprecipitation from $\mathrm{CHCl}_{3} / \mathrm{CH}_{3} \mathrm{OH} ;{ }^{\mathrm{c}}$ Estimated by $\mathrm{GPC}$ calibrated on polystyrene standards.
} 
summarizes the results of the polycondensation. According to a previous report, ${ }^{23}$ a control experiment without the additive smoothly proceeded and gave the corresponding polymer (Polymer 1) in good yield (entry 1). In contrast, the addition of succinimide did not give the polymeric product even after a prolonged reaction (entry 2), indicating that the byproduct of bromination with NBS prohibited direct arylation, presumably due to the formation of palladium-succinimide complex, ${ }^{39}$ which may deactivate the catalytic system. Alternatively, the polycondensation reaction proceeded smoothly in the presence of BTMA Br (entry 3); Wang et al. have elaborated on positive and negative effects of the addition of phase transfer agents on the direct arylation polycondensation. ${ }^{36}$ The addition of zinc chloride slightly reduced the catalytic activity, but increasing the reaction time to $48 \mathrm{~h}$ afforded the polymeric product (entry 4).

Based on these observations, we finally examined the sequential $\mathrm{Pd}$-catalyzed direct arylation polycondensation; the bromination reaction mixture was used without purification for the successive polycondensation (Scheme 3 (a)). The sequential protocol gave Polymer 1 with a molecular weight of 34,500 , in $80 \%$ yield. Polymer 1 obtained from the sequential protocol was characterized by NMR spectroscopy, Matrix Assisted Laser
Desorption/Ionization Time-of-Flight Mass Spectrometry (MALDI-TOF-MS), and elemental analysis. As shown in Figure 1 , the ${ }^{1} \mathrm{H}$ NMR spectrum of Polymer 1 prepared via the sequential protocol essentially agrees with that of the polymer obtained from the isolated pure 2,7-dibromo-9,9-dioctylfluorene. Each ${ }^{1} \mathrm{H}$ NMR signal can be assigned to the repeating unit; the integral ratios of the signals agree with the assignments and are consistent with the alternating structure of the polymer. $A{ }^{13} \mathrm{C}\left\{{ }^{1} \mathrm{H}\right\}$

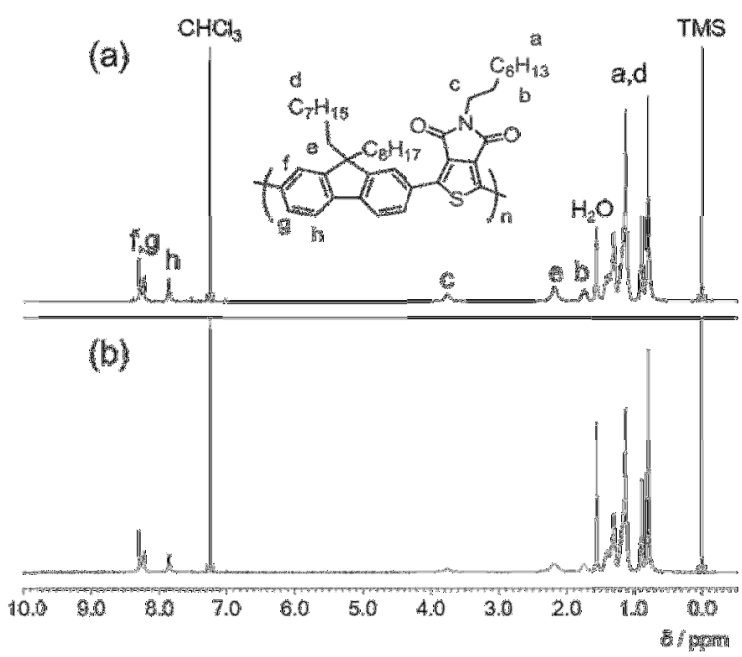

Figure 1. ${ }^{1} \mathrm{H}$ NMR spectra of Polymer 1 (400 $\mathrm{MHz}$, in $\mathrm{CDCl}_{3}$ ). (a) Synthesized via sequential protocol (Scheme $3(\mathrm{a}))$ and (b) synthesized from the isolated 2,7-dibromo-9,9dioctylfluorene (Scheme 2, Table 1, Entry 1).

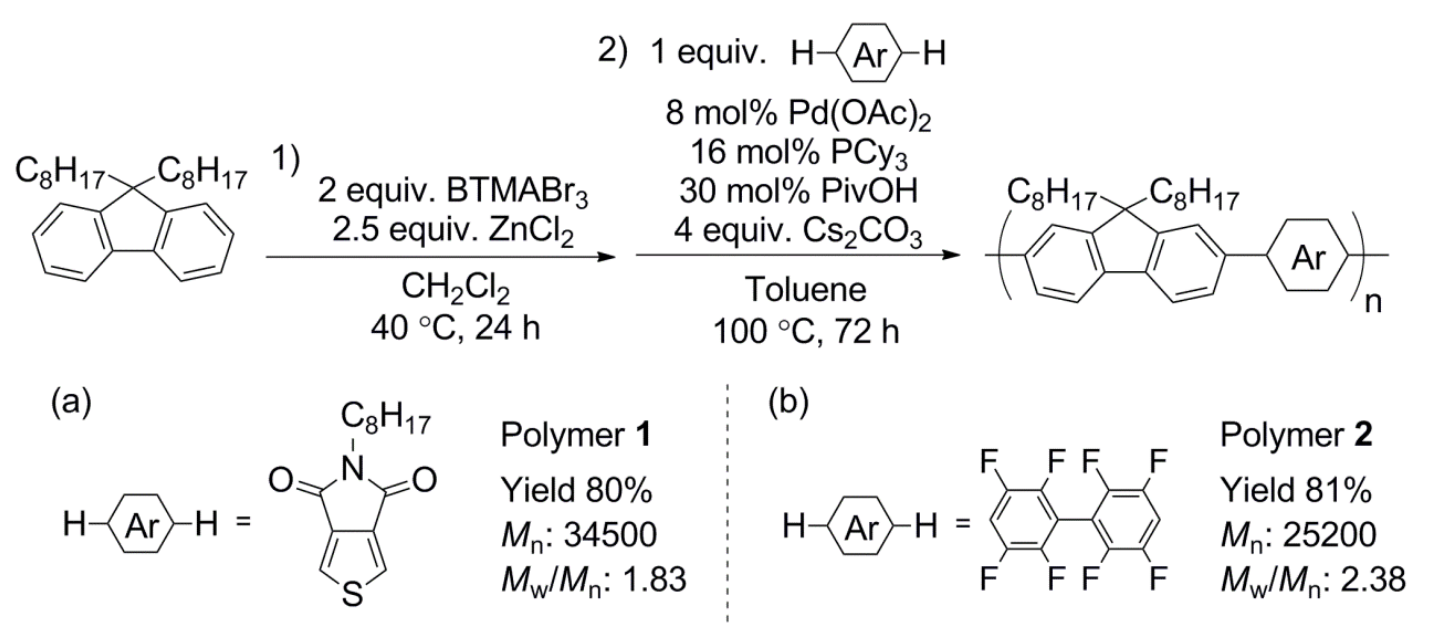

Scheme 3. Sequential bromination of 9,9-dioctylfluorene and direct arylation polycondensation with

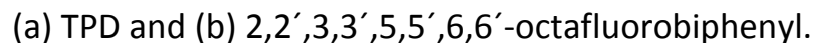


NMR signals are also assignable to the carbons in the recurring unit (Figure 1S, supporting information). The MS spectrum exhibits peaks at regular intervals in the measurable molecular weight range, corresponding to the structure of the linked fluorene and TPD units (Figure S2, supporting information). The absorption spectra of the obtained polymers are also essentially identical (Figure S3, Supporting Information), and the optical bandgap is determined to be $2.45 \mathrm{eV}$. Consequently, the difference in the synthetic protocols does not affect the chemical structure and optical properties of the polymers.

The sequential protocol was further demonstrated by the polycondensation of 9,9dioctylfluorene with $2,2^{\prime}, 3,3^{\prime}, 5,5^{\prime}, 6,6^{\prime}$ octafluorobiphenyl (Scheme 3 (b)); the direct arylation polycondensation of the isolated pure 2,7-dibromo-9,9-dioctylfluorene and $2,2^{\prime}, 3,3^{\prime}, 5,5^{\prime}, 6,6^{\prime}$-octafluorobiphenyl gave the corresponding polymer with a molecular weight of 43,200 in $95 \%$ yield. $^{26}$ The sequential protocol afforded the corresponding polymer (Polymer 2) with a molecular weight of 25,200 in $81 \%$ yield. The NMR and absorption spectra essentially agreed with those in previous reports (Figure S5-7, 9, Supporting Information). ${ }^{26}$ These results were consistent with the trend observed in the synthesis of Polymer 1.

In summary, the synthesis of fluorene-based $\pi$ conjugated polymers via sequential bromination and direct arylation was demonstrated. Bromination of 9,9dioctylfluorene using BTMA $\mathrm{Br}_{3}$ efficiently proceeded and barely inhibited the following direct arylation polycondensation, successfully giving $\pi$-conjugated polymers. Currently, the polycondensation reaction conditions are very specific towards the targeting monomer being electron-poor, and established conditions would be required for the electron-rich one. ${ }^{23}$ However, this is the first example of the facile synthesis of $\pi$-conjugated polymers in a one-pot fashion, without the need for prior preparation and purification of dibrominated aromatic monomers as well as organometallic monomers, and the bromination reaction using $\mathrm{BTMA} \mathrm{Br}_{3}$ is also available to other aromatic compounds such as thiophene $\mathrm{e}^{21,22}$ and carbazole derivatives (Scheme S2, Supporting Information). Therefore, the fundamental findings described here should present new insights for the synthesis of $\pi$-conjugated semiconducting materials using the step-economical protocol. Further studies, including availability of the synthetic protocol for other aromatic monomers and evaluation of electrical properties of the polymers are currently underway in our laboratory.

\section{EXPERIMENTAL}

\section{Sequential bromination of 9,9-dioctylfluorene and Pd-catalyzed direct arylation polycondensation with 5-octylthieno[3,4- c]pyrrole-4,6-dione}

A catalyst solution was prepared in advance using the following procedure: a mixture of $\mathrm{PCy}_{3}$ (239 mg, $0.852 \mathrm{mmol}$ ), Pd(OAc) 2 (95.7 mg, 0.426 $\mathrm{mmol})$, and anhydrous toluene $(4.25 \mathrm{~mL})$ was stirred at room temperature overnight under nitrogen atmosphere. The resulting mixture was used as a catalyst solution $\left(\mathrm{PCy}_{3}: 0.200 \mathrm{~mol} / \mathrm{L}\right.$, $\left.\mathrm{Pd}(\mathrm{OAc})_{2}: 0.100 \mathrm{~mol} / \mathrm{L}\right)$.

A mixture of dried $\mathrm{ZnCl}_{2}(170 \mathrm{mg}, 1.25 \mathrm{mmol})$, 9,9-dioctylfluorene (195 mg, $0.500 \mathrm{mmol}$ ), anhydrous dichloromethane $(2 \mathrm{~mL})$, and BTMA $\mathrm{Br}_{3}$ (390 mg, $1.00 \mathrm{mmol}$ ) was stirred for $24 \mathrm{~h}$ at $40{ }^{\circ} \mathrm{C}$ under nitrogen atmosphere. After the mixture was cooled to room temperature, anhydrous toluene $(1 \mathrm{~mL})$ and $\mathrm{Cs}_{2} \mathrm{CO}_{3}(652 \mathrm{mg}$, $2.00 \mathrm{mmol}$ ) were added and stirred for $1 \mathrm{~h}$. Then, TPD (133 mg, $0.500 \mathrm{mmol}$ ), catalyst solution $\left(0.400 \mathrm{~mL}\right.$ including $\mathrm{Pd}(\mathrm{OAc})_{2}(0.0400$ $\mathrm{mmol})$ and $\left.\mathrm{PCy}_{3}(0.0800 \mathrm{mmol})\right)$, pivalic acid (PivOH) (0.0169 mL, $0.150 \mathrm{mmol})$, and anhydrous toluene $(1.1 \mathrm{~mL})$ were added to the mixture. The resulting mixture was stirred at $100{ }^{\circ} \mathrm{C}$ for 72 h. After cooling to room temperature, the mixture was diluted with $\mathrm{CHCl}_{3}(100 \mathrm{~mL})$ and then washed with $1 \mathrm{M} \mathrm{HCl}$ 
solution $(50 \quad \mathrm{~mL} \quad \times \quad 3), \quad 0.1 \quad \mathrm{M}$ ethylenediaminetetraacetic acid disodium salt (pH 8) $(50 \mathrm{~mL} \times 3)$, and distilled water $(50 \mathrm{~mL} \times$ $3)$. The organic layer was dried over sodium sulfate and filtered through a Celite plug. The solution was concentrated under reduced pressure and precipitated in $\mathrm{CH}_{3} \mathrm{OH}$. The polymer deposit was washed with $\mathrm{CH}_{3} \mathrm{OH}$ and hexane. The solid was reprecipitated from $\mathrm{CHCl}_{3} / \mathrm{CH}_{3} \mathrm{OH}$, giving poly[(9,9-dioctylfluorene2,7-diyl)-(5-octylthieno[3,4-c]pyrrole-4,6-dione1,3-diyl)] (Polymer 1 ) as a yellow solid in $80 \%$ yield $\left(M_{\mathrm{n}}=34500, M_{\mathrm{w}} / M_{\mathrm{n}}=1.83\right) .{ }^{1} \mathrm{H} \operatorname{NMR}(400$ $\mathrm{MHz} \mathrm{CDCl}_{3}$ ): $\delta 8.20-8.31(\mathrm{~m}, 4 \mathrm{H}), 7.86(\mathrm{~d}, J=8.0$ $\mathrm{Hz}, 2 \mathrm{H}), 3.75(\mathrm{br}, 2 \mathrm{H}), 2.18(\mathrm{br}, 4 \mathrm{H}), 1.74(\mathrm{br}, 2 \mathrm{H})$, 0.60-1.47 (m, br $43 \mathrm{H}) .{ }^{13} \mathrm{C}\left\{{ }^{1} \mathrm{H}\right\} \operatorname{NMR}(150 \mathrm{MHz}$, $\left.\mathrm{CDCl}_{3}\right): \delta 163.1,152.4,145.2,142.2,130.5$, 130.2, 127.4, 122.8, 120.6, 55.8, 40.1, 38.7, 31.8, 30.0, 29.3, 29.2, 28.6, 27.1, 23.93, 22.7, 22.6, 14.1. Anal. calcd. for $\mathrm{C}_{43} \mathrm{H}_{57} \mathrm{NO}_{2} \mathrm{~S}: \mathrm{C} 79.21, \mathrm{H}$ 8.81, N 2.15; found C 78.99, H 8.61, N 2.27.

\section{ACKNOWLEDGEMENTS}

This research was partly supported by a Grantin-Aid for Scientific Research (25810070, 25288052, and 25620094) from MEXT, the Industrial Technology Research Grant Program in 2011 from NEDO. The authors thank the Chemical Analysis Division and the OPEN FACILITY, Research Facility Center for Science and Technology, University of Tsukuba, for the measurements of NMR, MALDI-TOF-MASS, and elemental analysis.

\section{REFERENCES}

1. L.-C. Campeau, K. Fagnou, Chem. Commun. 2006, 12, 1253.

2. D. Alberico, M. E. Scott, M. Lautens, Chem. Rev. 2007, 107, 174.

3. R. Rossi, F. Bellina, M. Lessi, C. Manzini, Adv. Synth. Catal. 2014, 356, 17.

4. T. Satoh, M. Miura, Chem. Lett. 2007, 36, 200.

5. L. Ackermann, R. Vicente, A. R. Kapdi, Angew. Chem., Int. Ed. 2009, 48, 9792.
6. Y. Segawa, T. Maekawa, K. Itami, Angew. Chem. Int. Ed. 2015, 54, 66.

7. K. Okamoto, J. Zhang, J. B. Housekeeper, S. R. Marder, C. K. Luscombe, Macromolecules 2013, 46, 8059.

8. L. G. Mercier, M. Leclerc, Acc. Chem. Res. 2013, 46, 1597.

9. S. Kowalski, S. Allard, K. Zilberberg, T.Riedl, U. Scherf, Prog. Polym. Sci. 2013, 38, 1805.

10. A. E. Rudenko, B. C. Thompson, J. Polym. Sci., Part A: Polym. Chem. 2015, 53, 135.

11. J. Kuwabara, T. Kanbara, J. Synth. Org. Chem., Jpn. 2014, 72, 1271.

12. M. Sévignon, J. Paillon, E. Schulz, M. Lemaire, Tetrahedron Lett. 1999, 40, 5873.

13. Q. Wang, R. Takita, Y. Kikuzaki, F. Ozawa, J. Am. Chem. Soc. 2010, 132, 11420.

14. X. Wang, K. Wang, M. Wang, Polym. Chem. 2015, 6, 1846.

15. P.-O. Morin, T. Bura, B. Sun, S. I. Gorelsky, Y. Li, M. Leclerc, ACS Macro Lett. 2015, 4, 21.

16. K. Nakabarashi, M. Yamada, H. Mori, Bull. Chem. Soc. Jpn. 2015, 88, 222.

17. S. Kajigaeshi, T. Kakinami, M. Moriwaki, T. Tanaka, S. Fujisaki, T. Okamoto, Bull. Chem. Soc. Jpn. 1989, 62, 439.

18. S. Kajigaeshi, T. Kakinami, H. Tokiyama, T. Hirakawa, T. Okamoto, Chem. Lett. 1987, 627.

19. S. Kajigaeshi, T. Kakinami, K. Inoue, M. Kondo, H. Nakamura, M. Fujikawa, T. Okamoto, Bull. Chem. Soc. Jpn. 1988, 61, 597.

20. S. A. Pourmousavi, P. Salehi, Acta Chim. Slov. 2009, 56, 734.

21. T. Okamoto, T. Kakinami, H. Fujimoto, S. Kajigaeshi, Bull. Chem. Soc. Jpn. 1991, 64, 2566.

22. A. Lange, H. Krueger, B. Ecker, A. V. Tunc, E. von Hauff, M. Morana, J. Polym. Sci. Part A: Polym. Chem. 2012, 50, 1622.

23. J. Kuwabara, K. Yamazaki, T. Yamagata, W. Tsuchida, T. Kanbara, Polym. Chem. 2015, 6, 891.

24. W. Lu, J. Kuwabara, and T. Kanbara, Macromolecules 2011, 44, 1252.

25. M. Wakioka, Y. Kitano, F. Ozawa, Macromolecules 2013, 46, 370.

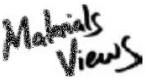

WWW.MATERIALSVIEWS.COM 
26. W. Lu, J. Kuwabara, T. lijima, $H$. Higashimura, H. Hayashi, T. Kanbara, Macromolecules 2012, 45, 4128.

27. Y. Fujinami, J. Kuwabara, W. Lu, H. Hayashi, T. Kanbara, ACS Macro Lett. 2012, 1, 67.

28. K. Yamazaki, J. Kuwabara, T. Kanbara, Macromol. Rapid Commun. 2013, 34, 69.

29. W. Lu, J. Kuwabara, T. Kanbara, Polym. Chem. 2012, 3, 3217.

30. S. J. Choi, J. Kuwabara, T. Kanbara, ACS Sustainable Chem. Eng. 2013, 1, 878.

31. W. Lu, J. Kuwabara, T. Kanbara, Macromol. Rapid Commun. 2013, 34, 1151.

32. S. Hayashi, Y. Kojima, T. Koizumi, Polym. Chem. 2015, 6, 881.

33. C. Xia, R. C. Advincula, Macromolecules 2001, 34, 5854.
34. Y. Liu, Q. Xiu, L. Xiao, H. Huang, L. Guo, L. Zhang, H. Zhang, S. Tan, C. Zhong, Polym. Adv. Technol. 2011, 22, 2583.

35. H. R. Mitchell, Y.-H. Lai, V. R. Williams, J. Org. Chem. 1979, 44, 4733.

36. X. Wang, M. Wang, Polym. Chem. 2014, 5, 5784.

37. H. Zhao, C.-Y. Liu, S.-C. Luo, B. Zhu, T.-H. Wang, H.-F. Hsu, H. Yu, Macromolecules 2012, 45, 7783.

38. N. I. Abdo, A. A. El-Shehawy, A. A. ElBarbary, J.-S. Lee, Eur. J. Org. Chem. 2012, 2012, 5540.

39. I.J.S. Fairlamb, A.R. Kapdi, J.M. Lynam, R.J.K. Taylor, A.C. Whitwood, Tetrahydron 2004, 60, 5711.

40. 


\section{GRAPHICAL ABSTRACT}

\section{AUTHOR NAMES}

Hitoshi Saito, Junpei Kuwabara, and Takaki Kanbara

TITLE

Facile Synthesis of Fluorene-based $\pi$-Conjugated Polymers via Sequential Bromination/Direct Arylation Polycondensation

\section{TEXT}

The synthesis of fluorene-based $\pi$-conjugated polymers via sequential bromination and Pd-catalyzed direct arylation polycondensation was demonstrated; the protocol allows dual functionalization of each aromatic monomer in one-pot fashion. This synthetic protocol afforded the corresponding polymers with high molecular weights in good yields (up to yield $80 \%, M_{\mathrm{n}} 34500$ ).

\section{GRAPHICAL ABSTRACT FIGURE}

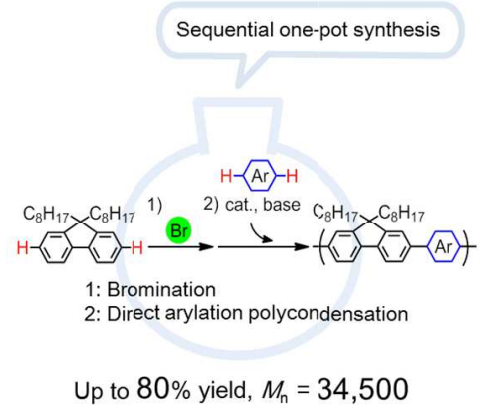

